\title{
Chemistry and the Community
}

$\mathrm{P}^{\mathrm{F}}$ ROF. J. C. PHILIP'S presidential address to Section B (Chemistry) of the British Association delivered on September 10, on the function and training of the chemist in the service of the community, was of much more general interest than many recent addresses or discussions in this Section but was ill-rewarded by a rather smaller attendance than is usual at the presidential address to the Section. While this may be due in part to the counter-attraction of several other discussions of wide appeal taking place at the same time, the attendance at least suggests that chemists are a long way from being alive to the social implications of their work. Prof. Philip's address, however, received the strong support of the Section, and apart from its endorsement by subsequent speeches, the approval which met many of his pertinent remarks, such as those concerning the abuse of chemistry for destructive purposes and his criticism of premature specialization and the absurdity of a university department of chemistry finding it necessary to teach its students German, was plainly manifest. Sir Josiah Stamp, who was present, spoke briefly but emphatically in agreement with Prof. Philip's views.

Mr. M. P. Applebey, who followed, discussed the particular relations between industry and the profession of chemistry. In dealing with the scope of the chemist in industry, he quoted from the joint Report of the Chemical Societies of the North East Coast to the District Commissioner for the Special Areas, which forms such an admirable example of the way in which the profession can assist in handling social problems. Despite the wide scope of the chemist's work in industry his importance is not fully realized in some industries, and industry in Great Britain does not employ its due proportion of trained chemists. The chemist is most widely recognized as an analyst, but even for this purpose men of meagre qualifications are often employed, while some firms seem to consider that analytical work exhausts the possibilities of trained assistance from the chemist. As a plant manager, he has equally important functions, and chemical processes in operation require study by controllers who understand their scientific basis if efficiency and progress are to be secured. With the wider recognition of the value of technical knowledge in sales service, the chemist is finding another outlet for his services. Mr. Applebey also commented on the purchase of processes from abroad by firms in Great Britain, and pointed out that such a policy can never be a substitute for a research policy. In the absence of a research department, considerable sums may be spent on processes which prove to be impracticable, and even perfectly good processes may require much research to adapt them to the particular conditions or to acquire the intimate knowledge of their chemistry essential for successful operation.

Mr. Applebey went beyond Prof. Philip in his remarks about the place of the chemist in management, strongly maintaining that an education in chemistry or any of the exact sciences affords as good a mental training for management as some longer established courses of education. Turning to the relations between industry and chemical education, he urged that industry first requires strong and active schools of research engaged in the pursuit of knowledge and the discovery of principles from which applications may flow. Industry also looks to the schools of chemistry for a supply of suitably trained chemists to fill such posts as have been indicated. For this purpose a good honours degree is desirable, but the honours course in chemistry should be soundly based on fundamentals, giving a firm grasp of principles. Preferably the recruit should have had two or three years of advanced experimental work, usually research, designed to develop perseverance and resource as well as technique. An industrial basis in such research is neither necessary nor desirable. Industry's obligations to chemical education are best discharged by the subsidizing of research through research scholarships, by grants for special apparatus and chemicals and the support of fundamental work and of chemical publications, both directly and through encouraging its technical staff to become members of one or more societies and participate in their work.

Mr. C. J. T. Cronshaw prefaced his paper on "the Benign Gifts of Organic Chemistry" with an endorsement of Prof. Philip's remarks regarding the need for a broad scientific basis of training. The better chemists entering the organic chemical industry are acquainted with neighbouring and borderland sciences, the better fitted they are for their job. The chemist should understand the uses to which his products are put and be able to measure and assess such properties so as to be able to improve them. Early specialization is a danger; the study of science alone is liable to produce men lacking in general culture, with little literary ability and incapable of expressing themselves clearly. General culture, he suggested, may be improved by a study of history from the angle of the rise of industries in modern times under the influence of scientific developments. Finally, Mr. Cronshaw urged that the industrial recruit should cultivate the power of eriticism and of co-operating with others in a team.

Mr. Cronshaw then gave a brilliant review of the development of industrial organic chemistry, commencing with the development of the dyestuffs industry and describing the myriad contributions of organic chemistry to our comfort and well-being to-day. 'The quest for colour, which in itself ministers to the need of many industries, has led the industrial organic chemist into many other fields, such as those of medicine in the provision of anæsthetics, and of remedies for sleeping sickness. As with dyestuffs, the tendency with progress is to advance from the general to the specific. The motor-car industry owes much to the organic chemist alike in the improvement of tyres, oil, petrol and the finishes used for it. Organic chemistry has given the textile industry two new fibres, and in its recent work on detergents and products for the control of pests and in the field of vitamins it is continuing to confer benefits on mankind.

Sir Henry Dale, in discussing the training of chemists for work in the fields of biochemistry and medicine, referred to the way in which chemistry in recent years has invaded the fields of functional biology and the sciences related to medicine. Even in the complex field of immunity, in recent years we 
have seen the beginning of exact description in terms of organic and physical chemistry. In the last few years a whole series of hormones has been isolated chemically and several synthesized. Four or five vitamins have been identified chemically and at least three synthesized. Sex hormones, one vitamin, carcinogenic substances and heart tonics have been chemically related to the typically inert sterols. Already new substances have been synthesized which promise to give control over some of the most deadly infections of man, especially in the tropics. The whole orientation of therapeutics is being shifted from the effects to the causes of disease. Sir Henry Dale suggested that the greatest service of chemistry to the community lies in this new and increasing domination of biological and medical research by chemical methods and ideas. In urging the necessity for co-operation between the chemist and those trained primarily in biology and the medical sciences, he protested strongly against the neglect in Great Britain of the study of tropical diseases. While we control more of the tropics than any other country in the world, we have done comparatively little in attacking the problems of tropical disease. It is unlikely that we shall be able to justify permanently the possession of large sections of the globe, and depend on the efforts of other nations to make them habitable.

\section{The Mediterranean Littoral}

$\mathrm{T}$

HE Consiglio Nazionale delle Ricerche has undertaken, through the agency of the National Committee for Geography in conjunction with the Institute of General Geography of the University of Pisa, an inquiry into recent conditions affecting sandy beaches along the Italian littoral, and in this connexion is publishing a series of monographs dealing with the coastline in ten regional sections, each of which is to form the subject of a separate volume. In this way, reviving the studies of eminent physiographers of the past, it is intended to present a ehain of facts which will serve for a systematic research into the regimen of Italian beaches and so foster the advancement of scientific geography, at the same time aiding in the development of maritime engineering.

The opening volume of the series, forming an introduction to the whole subject, has been prepared by Signor Agatino D'Arrigo*, an engineer of acknowledged competence and merit, who has received the distinction of the award of a premium from the Royal Academy of Italy for his publications on coastline phenomena. He has produced an excellent historical review of the subject, giving an account of the earlier investigations of Italian observers from Leonardo da Vinci, Montanari, Marsili and Paleocapa to Cialdi and Cornaglia, including at the same time appropriate references to the facts recorded by writers of other nationalities. The first part of the volume is taken up with this disquisition, and is followed by certain deductions of a general order to which limitations of space do not permit reference in detail.

The second part consists of a series of comparative morpholithological studies of the regimen of various parts of the Mediterranean littoral, including the Nile Delta, the Delta of the Po and the adjacent

* Ricerche sul Regime dei Litorali nel Mediterraneo. By Agatino D'Arrigo. Pp. 172. (Rome: Stabilimento Tipografico "Aternum".) 50 lire.
Venetian region, the Delta of the Rhone, the Delta of the Tiber, the Bay of Taormina, the Algerian Littoral and the Argentarian Promontory, with a final chapter embodying the conclusions of the author.

The investigations are obviously spread over a wide field and while they serve as an admirable introduction to a further and more complete survey, their immediate value is perhaps best assessed, as stated by Prof. Toniolo in his preface to the volume, as a general confirmation of the hypothesis already advanced of the probable reversibility of the cycle of evolution of the Mediterranean littoral. For physiographers of other nationalities, the book contains a great deal of serviceable information, with useful references to the work of Italian investigators. The treatise, in fact, is commendably documented, and there is an excellent set of coloured charts showing coastline changes at various dates. B. C.

\section{Educational Topics and Events}

Wild-Barfield Electric Furnaces, Ltd., Elecfurn Works, North Road, Holloway, London, N.7, have prepared a series of lantern slides illustrating many types of electric furnaces for heat-treatment, together with notes regarding the various slides. These form the basis of a paper on such equipment, and sets and lecture are available for societies, technical schools or other interested bodies.

Formax education for marriage is advocated by Paul H. Landis of the State College of Washington in an article on "Control of the Romantic Impulse through Education" published in School and Society of August 15. The mounting divorce rate in the United States, now higher than in any other country, is, he suggests, attributable in some measure to the frequency of romantic marriages, and of this the chief cause is the mobility characteristic of contemporary American life, especially in the West, where the divorce rate is highest. "In most fields now we believe in giving experience vicariously through books and the school curriculum, yet in the field of marriage and the family we let youth learn by experience." We need courses in high school and college in eugenies and the essentials of happy family life, to set up new barriers to the free exercise of the romantic urge.

The Education Act 1936 throws upon local education committees a heavy addition to their responsibilities. In persistently agitating for the raising of the obligatory school age, for which the new Act provides, they have, as an editorial in their official organ, Education, of September 4, points out, created for themselves a vast moral obligation. The issues involved in adjudicating upon applications for exemption closely concern the well-being of the community : the health and physical condition of the child; the 'beneficial' nature of the proposed employment, including its prospective benefit; the opportunities to be afforded of free education; the time available for recreation; and the case of each individual child will call for careful consideration. The grant of an employment certificate in respect of an exempted child is clearly intended to be a deliberate judicial act, not the routine application of a rough and ready test. An incidental advantag€ 